\title{
A construção da imagem da gastronomia nos cadernos de turismo
}

Tânia Siqueira Montoro

Dra. em comunicação audiovisual e publicidade pela Universidade Autônoma da Barcelona professora e pesquisadora da Faculdade de comunicação e do Centro de Excelência de Turismo da UnB.

Resumo: 0 artigo revela as formas que configuram a construção da imagem da gastronomia nos cadernos de turismo veiculados pelos jornais de maior circulação nacional. Compreendendo o espaço jornalístico como lócus de representação de identidades e configurações de imaginários, o trabalho, segundo uma análise conteudística e temática, oferece uma interpretação do discurso midiático, partindo das características estruturais desse texto/imagem, evidenciando a disposição hierárquica dos temas abordados, sublinhando os sentidos explícitos, implícitos e naturalizados que essa narrativa produz, provoca e convoca.

Palavras-chave: Cultura, turismo e gastronomia

Apresentação

A motivação para a análise dos cadernos de turismo veiculados pelos jornais impressos está amparada em minha atuação como professora e pesquisadora de duas áreas interdisciplinares: a comunicação e o turismo. A definiçāo co universo para análise das matérias de gastronomia dos cadernos de turismo considerou a importância do material empírico veiculado pelos jornais de circulação nacional e contemplou também o jornal de maior circulação no Distrito Federal, o Correio Braziliense. Desta feita, a amostra da pesquisa compreende os jornais do eixo Rio/São Paulo, de abrangência nacional, e o de maior circulaçáo no Distrito Federal. O material empírico foi classificado durante os meses de março, abril e maio de 2004 . Os jornais selecionados veiculam seus cadernos semanalmente, com os títulos "Boa Viagem", às quintas-feiras, em O Globo; "Folha Turismo", às segundas-feiras na Folha de S. Paulo, e "Lugares", às quartasfeiras no Correio Braziliense, do Distrito Federal.

Os cadernos foram analisados em seu conjunto informativo, destacando-se as matérias relacionadas ao turismo e à gastronomia. Considerou-se, para efeito de catalogação, a periodicidade da edição, o conteúdo e a forma de apresentaçáo da notícia; a temática com a divulgação mais freqüente, o atrativo ou destino turístico/ gastronômico oferecido ao leitor; os processos de individualização da gastronomia como atrativo turístico; a quantificação das matérias relacionadas à gastronomia dentro de um universo discursivo do caderno de turismo dos jornais, e a identificação dos roteiros gastronômicos indicados pela mídia impressa.

Durante a investigação, procedeuse ao estudo dos Cadernos de Turismo, com identificação e qualificação das matérias que amplamente se referiam à gastronomia, à culinária e à segurança alimentar: para efeito de classificação, a pesquisa identificou as temáticas recorrentes, estabelecendo um corte temporal e histórico dos cadernos, registrou o volume da informação oferecida ao leitor; mapeou diferenciais discursivos e de valoração da notícia, verificou pautas e agendas públicas, e desenhou modalidades de consumo e práticas culturais advindos dos destinos turísticos e gastronômicos apresentados pela mídia impressa.

Para este estudo, a gastronomia é concebida como uma prática cultural, considerando que o ato de comer não representa somente a satisfação das necessidades biológicas dos humanos, mas preenche também as funçóes simbólicas e sociais, favorecendo o processo de socialização entre segmentos, grupos, povos e naçóes. A diversidade cultural do Brasil oferece um "prato feito" para o 
estudo da imprensa especializada em turismo, na medida em que aponta novos hábitos de consumo, redefine padrōes culturais identitários e registra o papel da mídia na informaçáo e conformaçāo da opiniāo pública. Tenser $(2004)^{1}$ sublinha que a comida é um fenômeno cultural, com conteúdos simbólicos e cognitivos, que pode adquirir múltiplos significados: comida para ricos e pobres, para mulheres ou crianças, para doentes, para festividades ou luto.

Os hábitos alimentares são experiências consolidadas através do tempo e por isso se transformam em simbolismos e representaçóes culturais. A comensalidade encontra o auge de expressão durante as refeiçóes. Como estudiosa dos processos interpretativos da comunicação na cultura contemporânea, interessa-nos problematizar algumas questôes que pontuam esta investigação. Como se constrói a imagem da gastronomia nos cadernos de turismo veiculados pelos jornais analisados? Que representaçốes sociais sāo veiculadas? Como a gastronomia ajuda a revelar a identidade desses tantos "Brasis"? Quem fala pela gastronomia no cenário da mídia impressa? Que relações se estabelecem entre imagem, mídia, turismo e gastronomia no ambiente midiático (das mediaçōes) e nos processos de significaçāo cultural? Que formaçôes discursivas se configuram para imprimir orientaçóes de conteúdos na relação entre turismo e gastronomia? Como a imagem-símbolo da gastronomia qualifica os destinos turísticos no país?

\section{Quem lê tanta notícia?}

Em nossos dias, milhōes de leitores mundo afora consomem notícias e, por que não dizer? imagens. É um movimento diário, cujo objetivo maior é manter-se informado e atualizado antes a complexidade da vida moderna em sociedade. As notícias veiculadas pelos meios de comunicação organizam o mundo e criam sentidos, cuja finalidade principal é relacionar os processos de interação no cotidiano e, ao mesmo tempo, permitir ao cidadão consumidor relatos dos acontecimentos julgados significativos e interessantes.

O consumo de notícias está diretamente relacionado com as formas de inserção dos sujeitos na economia globalizada, um processo simbólico (Bourdieu, 1988) ${ }^{2}$ que atualiza e reatualiza os limites morais e éticos da vida em sociedade. As notícias são parte da criação desse imaginário coletivo, resgatando imagens arcaicas, narrativas híbridas, subordinando temas e episódios, selecionando os discursos autorizados e com credibilidade, orientando repertórios imagéticos, construindo consensos e provocando dissensos e necessidades de consumo.

Estudar notícias como manifestação cultural que permeia o processo de construção e interpretaçăo da realidade é um desafio, especialmente quando o foco da observação se dirige à forma como os acontecimentos são narrados, Significa trabalhar com categorias advindas da própria materialidade do texto/notícia, destacando as recorrências e ressonâncias explicitadas nas formaçōes discursivas, identificando o leitor preferencial a que se destina determinada notícia. Descartando os paradigmas corriqueiros que amparam as teses da objetividade jornalística, nos aproximamos da questão indicando que a subjetivação é a condição necessária para

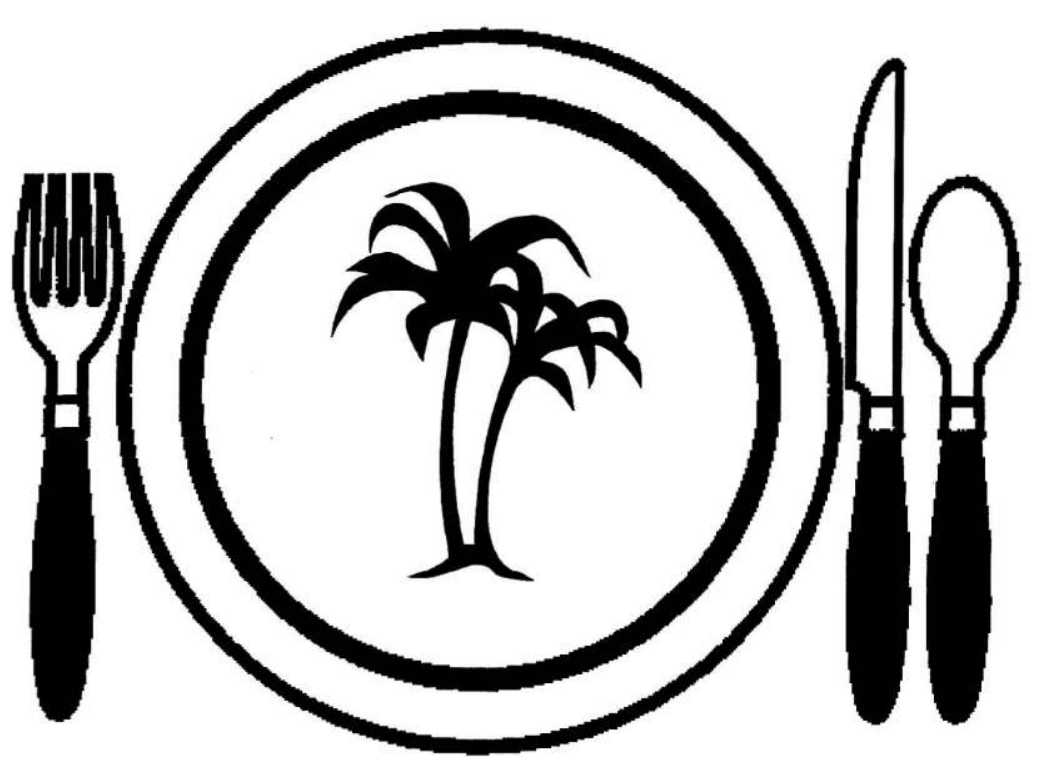

' Tenser, C. (2004) Uma leitura gastronômica na pesquisa acadêmica. Monografia apresentada ao curso de pós-graduação em Gastronomia e Segurança Alimentar, Centro de Excelência em Turismo da Universidad e de Brasilila.

\section{${ }^{2}$ Bourdieu, P. A economia das trocas lingüisticas.}




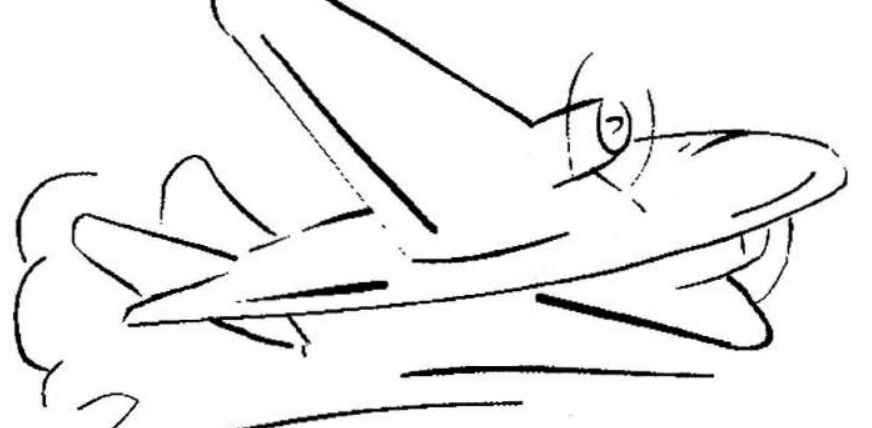

${ }^{3}$ Bird, E. e Dardenne, R. (1988). Myth, chronicle and story: exploring the narrative qualities of news. In: James Carey (ed) Media, Myth an narratives.

${ }^{4}$ Schudson, M. (1986), Reading the news.

${ }^{5}$ Tuchman, G. (1996) The study of routine news practice. in Paul Hirsch, Peter Miller e Gerald Kline (eds) Strategies for communication Research.

6Barthes, R. (1984). O rumor da
lingua.

' Filho, A. S. (2000:32) Cadernos de turismo:estudo comparado de edições de Brasilia, Rio de Janeiro e São Paulo. Monografia apresentada ao Centro de Excelência em Turismo da Universidade de Brasília. a construçāo de sentidos nos meios de comunicação, posto que a subjetividade é produto das relaçóes do homem com o ambiente e consigo mesmo, Nessa ambigüidade provocada pelo movimento homem/natureza/ ambiente/ cultura é que poderemos desvelar o liame que permite a sucessão de significados,

As notícias nos meios de comunicação desempenham o papel de contar histórias cotidianas a seus leitores, ávidos por informação e por novas possibilidades de entendimento dos acontecimentos. Funcionam como canais privilegiados de mediaçāo entre os fatos e os fenômenos que o rodeiam, e as narrativas sobre eles. É nesse jogo tacitamente consentido entre produtor e leitor, daquilo que é dito e do que é silenciado, que ocupa lugar, no universo das análises das notícias, o estudo sobre a produção de sentidos na narrativa jornalística. Para Bird e Dardenne (1988:265), ${ }^{3}$

Considerar as notícias como narrativas não nega o valor de as considerar como correspondentes da realidade exterior, afetando ou sendo afetadas pela sociedade, como um produto de jornalistas ou organizaçōes burocráticas, mas introduz uma outra dimensão às notícias, dimensão essa na qual as estórias das notícias transcendem as suas funçôes tradicionais de informar e explicar.

Diferentes autores (Schudson ${ }^{4}$, 1999; Tuchman' , 1996; Potter 2002) têm se debruçado sobre os estudos das notícias nas sociedades contemporâneas e oferecem uma reflexão crítica sobre os tipos de conhecimento que as notícias fornecem, descrevendo-as como um "mosaico" que privilegia o concreto, o particular e o individual. Os autores afirmam que a investigação científica sobre as notícias constitui, hoje em dia, um dos campos de pesquisa mais férteis $\mathrm{e}$ efervescentes dentro do vasto campo do media research, lembrando que os estudos das notícias datam de 1918, quando o sociólogo Max Weber as tomava como objeto de investigação.

O consumo de notícias é um hábito incorporado à modernidade, que apresenta a vida cotidiana como uma realidade interpretada pelos homens e subjetivamente dotada de sentidos, na medida em que constrói consensos. Para Barthes", "um texto é feito de escritas múltiplos, saídas de várias culturas e que entram umas com as outras em diálogo, no qual se revela o ser total da escrita-o leitor".

Perfil dos cadernos de turismo na mídia impressa

Segundo levantamento efetuado com os editores dos principais jornais brasileiros, Filho(2000:32) ${ }^{7}$ demonstra que os cadernos de turismo não são novidade na imprensa dessas últimas décadas. Pioneira no gênero, a Folha de S. Paulo publica, desde 1959, uma seção destinada ao turismo, inaugurando, em 1965 , o seu suplemento independente em circulaçāo. O jornal O Globo editou seu primeiro caderno de turismo em 1966, que em seguida passou a se chamar "Boa Viagem”, permanecendo até os dias atuais, O Jornal do Brasil circula com seu caderno de turismo desde 1976, e o Correio Braziliense, desde 1995.

Contando com uma equipe reduzida, geralmente formada por um editor, um subeditor e entre dois a quinze repórteres, os suplementos contam com a colaboração de outros jornalistas de empresas e alguns, como o Correio Braziliense, com matérias de free-lancers.

As pautas são variadas, tomando como destino o leitor médio de cada diário, as altas e baixas temporadas no setor, os lugares exóticos e, especialmente, os serviços oferecidos pelo trade de turismo. Os anunciantes pertencem, em sua maioria, ao trade, destacando-se, no sulemento da Folha de S. Paulo, as publicidades das agências de viagem e companhias de transporte aéreo; no jornal O Globo, a hotelaria e os restaurantes; e 
no do Correio Braziliense, as operadoras de turismo e os hotéis e restaurantes do entorno do Distrito Federal.

Apresentado pelo O Globo em formato tablóide e nos demais jornais, em formato jornal, possui pequeno sumário em sua apresentação. Por semana, identifica um destaque na capa, que geralmente ocupa de quatro a sete páginas. Outras matérias relativas à temática do turismo preenchem as demais páginas. As datas de comemoração nacional, como páscoa, dia dos namorados, dia das mães e dos pais, natal e feriados, orientam ediçóes destinadas à temática, especialmente quanto às novidades gastronômicas desses períodos.

Durante o período selecionado para análise, verificamos que as notícias sobre gastronomia, nos cadernos de turismo, ocupam em torno de $30 \%$ dos conteúdos noticiosos veiculados, variando de uma edição a outra. Em sua maioria, as matérias são de conteúdos promocionais de restaurantes, alimentos ou bebidas, excelência em serviços da hotelaria e destinos turísticos movidos pelas particularidades/ especificidades da gastronomia.

No quesito de notícias promocionais de restaurantes, registra-se que os jornalistas responsáveis pelas reportagens veiculadas, sem sua maioria, viajam a convite da empresa, que em contrapartida tem seu negócio veiculado como destaque na imprensa especializada. O leitor somente fica sabendo desse procedimento empresarial, que combina marketing com notícia, em um linha que registra "jornalista viajou a convite da empresa”. Registre-se que esse procedimento foge às regras elementares que orientam a ética no jornalismo.

Mídia, turismo e gastronomia: quando a mesa é um "prato feito"

Ao ler o jornal, o leitor toma conhecimento de fatos que, a priori, parecem estar restritos à circunscrição dos próprios acontecimentos, mas que com o avanço da narrativa, trazem outros significados ou criam novos sentidos. A narrativa jornalística baseada no evento cotidiano será tomada como categoria de análise e interpretaçāo cultural, focando as possibilidade que o texto jornalístico oferece para a gastronomia no destino turístico destacado.

Lugares gastronômicos: maratona das delícias do Correio Braziliense

Veiculado às quartas-feiras, o formato da página do jornal, o caderno possui em média oito páginas. Contém boxes informativos, utiliza fotografias, mapas, ilustraçóes e tabelas, facilitando serviços aos leitores. Sempre com um destaque, o caderno costuma apresentar dois outros temas por edição. A diagramação segue os mesmos padrōes do jornal que o abriga. É um caderno visual, com destaque para cenários de natureza exuberante, que ocupam, por vezes, quase página inteira ou servem de moldura para os textos mais curtos.

Boxes-padrão, chamados de "Pacotes", geralmente divulgam programas de viagem destinados ao local da matéria em destaque naquela edição. O boxe "Oriente-se" fornece dicas para viagem sublinhando pratos, restaurantes e bebidas que devem ser consumidos naquela localidade. O boxe "Informe-se" fornece outras informaçôes sobre o lugar e a viagem, sempre em linguagem acessível e tom intimista, mobilizando o diálogo com o leitor, Durante o período em análise, os títulos em destaque de capam no caderno do Correio Braziliense foram:"Chillan e Urmini, O calor do verão andino - Cordilheira dos Andes"; "As quatro maravilhas da Bélgica"; "Pipa: O mar é só o começo", Rio Grande do Norte (Brasil); "Programe agora o feriadāo da Semana Santa", com destaque para Pernambuco, Minas Gerais e Goiás Velho (Brasil); "Rio de Janeiro:Menos previsível mais interessante"; "Baixo Amazonas - O Oeste paraense que se quer mostrar ao mundo"; "Fonte de emoçāo", Foz do Iguaçi; "Sergipe: De Aracaju a Xingo"; "Grécia: Em ritmo de olimpíadas"; "Portugal: Contrastes lusitanos": "Festas juninas do Brasil". 
Verifica-se, pela análise das manchetes em destaque, uma preponderância de matérias de capa dedicadas ao turismo interno e, conseqüentemente, à gastronomia nacional.

As matériaś referentes $\AA$ gastronomia funcionam como formas estratégicas de agregação de valor ao destino turístico da ediçāo. $\mathrm{Na}$ matéria sobre a Cordilheira dos Andes, o caderno, em página interna orienta a leitura, com o subtítulo: "Pomares de frutas temperadas neste paraíso no Andes", e informa:

A alimentaçăo é em hora certa e boa, segundo os padrōes e pratos da culinária boliviana, Vá prová-la. Muito rica em variedades de verduras, grãos e especialmente de batatas. São conhecidas cerca de duas mil variedades e espécies de papas (batatas), mas existem cerca de $400 \mathrm{em}$ uso pelo povo, que tem predominância indígena. $\mathrm{O}$ cereal boliviano por excelência é a quinua (quinoa para nós). Na verdade, é da família do espinafre - é um espinafre que produz grãos. De tamanho muito pequeno, tem qualidades nutricionais extraordinárias. De fácil cozimento e assimilação, tem gosto levemente alcalino e uma variedade de formas de elaboração. Dizem os indígenas que uma dieta à base de quinoa, especialmente se estiver nas geladas altitudes andinas, ajuda os homens e as mulheres que têm baixa fertilidade.

Ao descrever as maravilhas da Bélgica, no segundo caderno de turismo do m es de março, e o romantismo de Brudges, conhecida como "Veneza do norte", a matéria chama a atençáo do leitor para um roteiro gastronômico pelos "bares, cafés, confeitarias e lojinhas de chocolate" e afirma que todo esse charme provoca uma lotaçáo "quase completa dos hotéis e restaurante o ano todo". Mas o destaque gastronômico da reportagem recai sobre os "pães da idade média".

O roteiro por Brudges apresenta curiosidades. Um exemplo é a casa de número 20 da rua Uitgezonderd
Plaatselijke onde funciona a padaria mais antiga da Bélgica, e talvez, da Europa. Lá os pães ainda são feitos como na Idade Média. Os vendedores náo se cansam de explicar aos visitantes os detalhes da arte de fabricar pães ao longo dos séculos, sem se irritar por ter de responder às mesmas perguntas todo santo dia.

Em outro trecho, a matéria revela "as tradicionais casas de chocolates que vendem desde barras tradicionais até produtos exóticos - como sutiãs de chocolate. Quando se trata de bebidas, a ênfase do discurso jornalístico recais sobre a "morte súbita", uma das cervejas mais fortes de toda a Europa, e um prato de "mexilhões com batata frita, a comida típica do país". A mistura de cerveja com frutos do mar é que convencerá o leitor/ viajante de que Brudges é, de fato, uma cidade muito mais do que especial.

Para caracterizar o destino turístico de Pipa, no Rio Grande do Norte, o discurso noticioso da matéria parte da "rua dos restaurantes para, elencando "creperias, pizzarias, casas especializadas em frutos do mar, ou em massas, cafés e até um boteco alcoólico transformado em galeria de arte", revelar a miscigenação da culinária na localidade, A gastronomia serve para localizar os leitores na mistura dos habitantes locais:

...italianos, argentinos, franceses convivem com nativos e conseguiram mesclara itens da culinária local com pratos tradicionais de seus países, como ravióli com recheio de gerimum - abóbora para os não iniciados no vocabulário nordestino ou pizza com frutos do mar de Pipa.

Na Semana Santa, a edição do caderno Lugares, em linguagem promocional e com formatação publicitária, divulgou os destinos mais representativos para se viver a paixão de Cristo e a Páscoa na tradição brasileira. A escolha recaiu sobre cidades singulares, como Recife, Olinda, Ouro Preto, Congonhas e São João del Rey, Goiás Velho ( ou Cidade de Goiás, como a rebatizaram os goianos) e ainda Gramado, 
"a terra do chocolate". Com o sugestivo nome de "Maratona de delícias", a reportagem adverte o leitor: "É bom ir bem preparado, seja adulto ou criança, para abandonar qualquer dieta". A reportagem descreve hábitos do consumo alimentar brasileiro:

O Brasil é o quinto no ranking mundial de consumo de chocolates e o segundo no consumo de balas, gomas de mascar e confeitos. $\mathrm{O}$ mercado brasileiro comercializou cerca de 50 toneladas a mais de chocolate no ano passado.

Em Minas e Goiás, as recomendaçōes para a Páscoa foram: "Os bons cafés coloniais, com bolos, biscoitos e sucos de frutas tipicas".

A parte mundana da festa santa ficou para a cidade de Vitória de Santo Antão, a $50 \mathrm{~km}$ de Recife, "que produz uma das marcas de aguardente mais famosas do mundo, a Pitu".

$\mathrm{Na}$ edição dedicada à cidade maravilhosa, a viagem gastronômica do caderno abusa das delícias dos frutos do mar preparados pelos cariocas e servidos em "restaurantes montados na varanda ou nos quintais das casas dos moradores na Barra da Tijuca". O grande destaque fica mesmo para alguns restaurantes e bares conhecidos dos brasileiros, seja pela tradição gastronômica, seja pela imortalização nas telas de cinema, por exemplo, o filme Bar Esperança, de Hugo Carvana, onde um grupo de amigos se une para evitar o fechamento de um bar - o qual está para ser derrubado e dar lugar a um grande empreendimento imobiliário. Partindo do filme, a matéria enfatiza o cardápio do Bar Luiz (onde foi rodada a película), que aposta numa variedade de pratos alemảes:

... salsichas, joelho de porco (eisbein), costela defumada (kassler), chucrute, chope preto e por aí vai. Lá é possível encontrar desde saladas até queijos fortes e bacalhau.

Para o passeio pela tradicional Confeitaria Colombo, freqüentada por intelectuais que passaram pela cidade maravilhosa, como Olavo Bilac, Rui Barbosa, Chiquinha Gonzaga e Getúlio Vargas, imortalizada em marchinhas carnavalescas e em cenários de filmes e telenovelas, o caderno dá a dica ao leitor:

Na hora do lanche, ou do chá da tarde, sucessos históricos da confeitaria recaem sobre os doces de Portugal pastel de nata, ovos moles e trouxinha de ocos, que no século 19 eram feitos por gente portuguesa mesmo. Há também um tal de toucinho do céu. Trata-se de um doce com amêndoas, ovos, muito açúcar, ótimo para o colesterol pular de tanta alegria.

Para salgados, o jornalista selecionou do roteiro gastronômico da tradicional Confeitaria: "... os petit-fours, biscoitinhos que nāo levam farinha (e sim castanba de caju) em sua massa".

A tradicional caipirinha, citada na matéria "Sob a proteção dos orixás", foi mencionada como "instituição nacional" e "bem imaterial da cultura brasileira".

Na matéria de destaque do caderno de turismo do CB de 28 de abril de 2004, a lendária regiāo amazônica é lembrada somente pelos cenários naturais e abundância de águas. Mesmo com a metáfora do subtítulo, "Histórias de mistério que apimentam a viagem", o leitor não possui esse condimento na informação sobre comida e hábitos alimentares e gastronômicos da região. Ao contrário, em diferentes roteiros propostos, o conselho é um só:

“... é preciso que o visitante leve um bom estoque de comida e bebida para desfrutar os prazeres da ilha de Tapajós, Os restaurantes săo escassos e oferecem apenas comida caseira".

Resta ao leitor a complexa aventura de descobrir o que é comida caseira nas singulares ilhas amazônicas habitadas por populaçôes nômades...

Sem possibilidades gastronômicas fica também a matéria de capa do caderno, dedicada a Foz do Iguaçu. Os vinhos da região, os doces típicos do sul brasileiro, churrascos e formas de preparar o pescado foram silenciados pelo discurso de
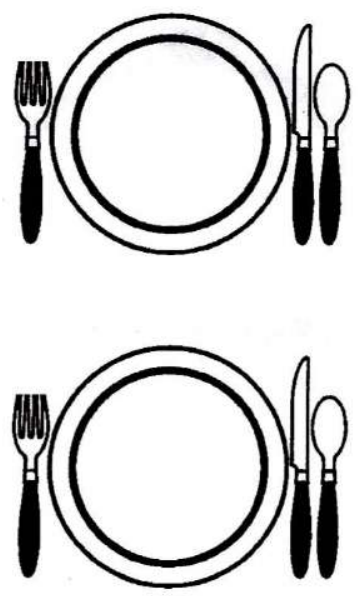
promoção do segundo destino mais procurado pelos estrangeiros que desembarcam no Brasil. Isso revela um hiato na comunicação do trade de turismo, que se vale tão somente das belezas naturais do parque, dos esportes de aventura que podem ser praticados, olvidando se as noites e a gastronomia como um aliado importante na promoção do turismo.

Mas, quando o destino é Sergipe, - leitor passeia pelos mercados descobrindo detalhes da culinária que, adverte o discurso midiático, "só existe por ali”. No mercado Antônio Franco, vale:

Uma passadinha no boxe do Erílio, laticínio dois irmãos, onde se pode saborear e levar para casa o famoso queijo de coalho, balas de araçá, castanha de caju doce ou salgada. $\mathrm{Ou}$ na barraca da Jô, que, espertamente, mexe os doces no tacho bem na hora do almoço. É impossível resistir aos copinhos de doce de banana, caju, pão, jaca, goiaba.

Destaca ainda o café da manhã do sergipano, que troca o pão francês pela "macaxeira e o cuscuz". Em termos de pratos regionais, o roteiro gastronômico sugere:

... pirão de capão, que é um caldo feito de frango novo - ou, como diz o Gonzaga, frango mocinho-e os pratos de caranguejo e camarão servidos durantes os passeios de barcos.

Os pratos de camarão e caranguejo ganham detalhes em fotografia no alto da página, com a seguinte legenda: " $O$ camarão servido durante o passeio turístico: tira-gosto que, assim como o caranguejo, aguça o paladar do sergipano e do visitante".

O ritual da quebra de caranguejos, que se repete aos finais de tarde, na orla da praia de Atalaia, é consagrado como "um barato". Destrinchar os cascudinhos serve de mote noticioso para denúncia do desaparecimento dos caranguejos na regiāo, seja "pelo crescimento desordenado da especulação imobiliária", ou "pela catação indiscriminada que não perdoa os filhotes nem na época do defeso, quando é proibida a pesca".
Dentre as maravilhas de Atenas reportadas no caderno de turismo de 121 05 , com a manchete "Grécia e as olimpíadas", é oferecida ao leitor dica no roteiro gastronômico:

... não deixe de provar a famosa sopa de pimenta, muito recomendada e preparada também com vegetais e carnes. Aliás, a carne preferida dos nativos é a carne de carneiro, que não deixa de ser gostosa, mesmo para quem não está habituado. Entre os vegetais destacam-se a alcachofra e a berinjela, todos regados com muito azeite de oliva, sempre puro e de grande qualidade. Mas há também os peixes e frutos do mar variados, afinal a Grécia tem um mar fabuloso. Como curiosidade năo deixe de provar o churrasquinho grego, feito em grandes espetos giratórios, inclusive nas ruas.

Compondo o roteiro das ilhas, a dica ao leitor/turista que for "acompanhar a novidade" é para

... experimentar o vinho produzido em Santorini, um dos melhores da Grécia. É feito com três variedádes de uvas Assytiko, a mais conhecida, Athiri e Aidanti-e o preço e bem interessante.

Além do hibridismo gastronômico, a matéria convida o leitor a conhecer um pouco mais os brasileiros nordestinos, como o presidente Lula. E afirma a fama de Caruaru como o local do maior "São João do mundo", enfatizando que a fama vem da culinária local. No período junino, o turista se esbanja com:

...muito milho cozido e assado, pamonha, canjica, arroz doce, pé-demoleque, e bolo de milho, entre outras delícias nordestinas. Mas o que encanta mesmo, ou assusta, dependendo da fome do foliāo, são as atraçóes gigantes. $\mathrm{Na}$ festa do ano 2000 , por exemplo, foi preparada um pamonha de $200 \mathrm{~kg}$, feita em um fogão de 60 bocas em plena rua. E tem também $500 \mathrm{~kg}$ de arroz doce, um tonelada de pé-de-moleque e duas broas de milho. Tudo isso regado ao tradicional quentão. 
O caderno "Viagem" do jornal O Globo, publicado às quintas-feiras, é veiculado no formato tablóide. Utiliza um pequeno sumário para apresentar as mais de 40 páginas de cada edição. Fotos, mapas, gráficos configuram o discurso promocional do turismo no encarte.

Possui três colunas fixas: "Via aérea", "Serviços" e uma coluna que destaca uma das capitais do mundo, escrita por correspondentes do diário no exterior. É recheado de todas formas de publicidade, concentradas especialmente numa de classificado, "Guia Boa Viagem", que ocupa as sete páginas finais do suplemento. Nele, hotéis, pousadas e pacotes turísticos e gastronômicos săo oferecidos para todo tipo de leitor/consumidor.

A coluna "Via Aérea" divulga novidades na agenda de eventos relacionados ao trade de turismo. Na coluna de "serviços" encontram-se informaçōes detalhadas sobre companhias aéreas de diversos países, contatos na Internet, telefones úteis para retirada e atualização de passaportes, cotação do dólar, euro, peso, etc; tabela de fusos horários, necessidade de vistos para viagem, equivalência de numeraçāo de vestuário de um país para outro. Na coluna "Capitais", uma reportagem extensa sobre alguma capital do mundo é veiculada semanalmente.

Verificamos ainda que o suplemento de turismo de $\mathrm{O}$ Globo apresenta o amior volume de publicidade de empresas de transporte aéreo e fluvial e dentre os jornais analisados.

Observa-se que as matérias de gatronomia estão estreitamente relacionadas com a capital do destino turístico em destaque naquela ediçāo, e versam, em sua maioria, sobre indicaçôes de restaurantes, pratos típicos e "comidinhas" dos destinos, singularizados em cada versão do tablóide. Essas capitais não precisam ser, necessariamente, a capital política e administrativa dos Estados; o substantivo capital serve para agregar valor de síntese e, por isso, Gramado é, assim, "a capital do chocolate"; a região da Chapada dos Veadeiros, "a capital dos esotéricos que buscam conforto"; Caruaru, "a capital do forró", e assim por diante.
O turismo do Estado do Rio é um dos destaques no jornal carioca, nos destinos reservados às praias, serras, cidades históricas e pequenas localidades rurais. Paraty, Angra dos Reis, Itaipava, Maricá, Região dos Lagos, Visconde de Mauá são destinos do Estado do Rio sublinhados no tablóide.

Indicando uma viagem a Paraty / RJ, apelidada pelo suplemento como "capital da celebração", o roteiro indica uma passa pela fazenda Engenho d'Ouro, que fica a oito quilômetros do centro histórico, para apreciar: "... o alambique que produz cerca de 70 litros de cachaça por dia e funciona com a força da água".

Depois de desfiar todo passeio gastronômico pela fazenda, sugere: "Degustar e comprar garrafas de aguardente. Há pingas envelhecidas, com melado, cravo, canela e folha de tangerina".

Numa reportagem sobre a regiāo de Itaipava, no Rio de Janeiro, intitulada "A Páscoa no Cardápio", a matéria é introduzida com a seguinte manchete:

Há tempos a regiāo de Itaipava e arredores virou pólo gastronômico. Mas o melhor é que sempre há boas $\mathrm{e}$ deliciosas novidades e os já tradicionais restaurantes estăo sempre inventando bons motivos para nova visita.

A matéria promove bons restaurantes com comida italiana, sob o comando do chef Danio Braga, e o "restaurante/pousada no Vale do Florido, que acaba de ser incluído no seleto guia francês Les Grandes Tables du Monde".

Tomando os destinos títulos de cada suplemento, sublinhando o discurso gastronômico em circulação, nessas reportagens, verificamos que a rotina de uma viagem ao Pantanal começa antes do café da manhã: "... a base de chipas - pães de queijo pantaneiros, bolos, mate, guaraná e frutas típicas da regiäo".

A boa comida pantaneira é revelada como uma mistura de carne seca e de mandioca, em múltiplas variaçōes. Para o período vespertino, o roteiro sugere:

No lanche da tarde, sugere-se beber tereré, chá feito com carias partes do 
"É um pouquinho pesado, mas depois de dois dias você pensa em repetir. $E^{\prime}$ o tal espirito de pura vida".

A gastronomia francesa é apresentada ao leitor na imagem midiática "da capital dos restaurantes e cafés, Paris". $\mathrm{Na}$ segunda quinzena de maio, em uma das ediçôes do tablóide, recomenda-se a ida ao restaurante Fish La Boissonerie, que possui "... uma adega farta com vinhos raros e bons peixes preparados com ervas aromáticas".

Fomentando do discurso de prestação de serviços ao leitor, a notícia adverte que o preço média da comida nesse estabelecimento nāo sai por menos do que "40 euros por pessoa, sem

ramo da planta e tomado numa guampa, como o chimarrão, mas sempre gelado, para amenizar o calor e recobrar a energia.

Depois de um dia de muita contemplação da natureza, o leitor pode escolher entre o ócio e o "fogo de chão", que é:

... um churrasco pantaneiro, acompanhado por violeiros, a costela de boi, a maminha, a picanha e outros cortes cozinhando ao calor da brasa de madeiras aromáticas, como o angico, que tornam a carne ligeiramente defumada ao sabor da madeira, e, numa grande mesa, variedades de arroz carreteiro, mandiocas, pães, farofas, saladas, frutas, compotas. Não esquecer do delicioso caldo de piranha que, vira e mexe, faz parte do cardápio de qualquer restaurante no Pantanal.

Apresentando a Costa Rica turística, o tablóide enfatiza pontos exóticos do destino, valendo-se do hábito alimentar de consumir p "casado", que é considerado "o prato feito de lá", degustado no café da manhã: “... o galo pinto, prato mundial do país, trata-se de um arroz com feijäo temperado, encarado à 7 da matina, com o estômago vazio".

Em diálogo com o espanto do leitor brasileiro, que nâo possui o hábito alimentar de consumir arroz com feijāo no café da manhā, o discurso conclui: bebidas". O chef do restaurante, o único com voz na matéria, justifica o preço "salgado" agregando valor aos pratos, em função da originalidade das receitas e pelo "ambiente tranqüilo e charmoso" do restaurante.

Turismo "à paulista" é na segunda-feira A Folha Turismo

O caderno de turismo do Jornal Folha de S. Paulo / Folha Turismo circula às segundas-feiras. Como os demais cadernos de turismo, a "Folha - Turismo", veiculada em tamanho jornal, apresenta diagramação visual em conformidade com os traços gráficos dos demais cadernos do jornal, como "Folha Esporte", Folha - Cotidiano", "Folha Dinheiro" etc. Em cada edição apresenta um destaque turístico, que pode ser um país, uma localidade ou uma região. As matérias destacadas na capa costumam ocupar as seis primeiras páginas do suplemento e contêm reportagens mais longas e com cobertura de maior profundidade.

"Giro pelo mundo" é uma das colunas fixas do caderno,onde, numa trama discursiva mobiliza-se a polissemia entre textos, fotografias e legendas, construindo uma narrativa caleidoscópica permeada sempre por uma dimensão cultural no trato do turismo e da gastronomia de cada regiāo. Nessa coluna escreve-se de tudo um pouquinho, de 
notícias de ataque de tubarôes a turistas nas praias de recife a descobertas de vitaminas para longevidade, ou ainda, descreve o elenco de propriedades do vinho para combater radicais livres, A coluna "Panorâmica" apresenta notícias relacionadas ao turismo, como inauguração de hotéis, restaurantes, construção de flats e lofts, lançamentos de livros em restaurantes e cafés, consumo de determinados alimentos por personalidades e "famosos" (substantivaçăo do adjetivo fama), eventos gastronômicos etc. Toda essa coluna é alimentada por notas, que não ultrapassam 20 linhas,

A coluna dedicada a "Turismo e Hotéis" é um classificado de pousadas, hotéis, albergues, cada de visitas, spas, hotéis-fazenda, oferecendo ao leitor uma série de descontos. Muitos anúncios dos classificados são das empresas que veiculam publicidade no suplemento. A dimensão cultural do caderno Folha Turismo o singulariza perante os demais analisados. Cinema, turismo, gastronomia se cruzam nas páginas do suplemento, assim como ópera e consumo de vinhos, música e destinos gastronômicos.

O conhecido "gosto refinado do paulistano" encontra seu ápice na oferta de consumo cultural do suplemento. Não se viaja, na Folha -Turismo, para conhecer lugares: conhece-se lugares especiais através de uma rota selecionada, que conta com um singular menu cultural preparado pelos repórteres, que parecem orientados a promover a informação cultural relacionando-a às rotas culturais selecionadas para matérias e reportagens. Em todas ediçóes, o suplemento abriga uma matéria destacando um destino turístico ou gastronômico na capital ou no interior de São Paulo.

De todos os suplementos analisados, o Folha - Turismo apresenta o maior volume noticioso registrado relacionando cultura/turismo e gastronomia. "O destino Espanha", destacado em 24 de maio, explicita a afirmação. Na edição de capa, o destaque jornalístico recai sobre as cavas da região da Catalunya/Espanha, com o título

"Catalunha borbulhante" e, na contracapa, em letras titulares, assertiva "Espumante atrai turistas a cidade Catalā". No subtítulo, a revelação de como a gastronomia agrega valor ao destino turístico espanhol: "Interesse pela cava levou, em 2003, 300 mil turistas a Sant Sadurni d'Anoia, a $50 \mathrm{~km}$ de Barcelona".

$\mathrm{Na}$ reportagem com fotos e legendas de divulgaçāo promocional, o Museu da Cava é colocado em perspectiva de primeiro plano. $\mathrm{O}$ museu, que faz parte do patrimônio nacional espanhol desde 1976, em Sant Sadurno d'Anoia, é revelado ao leitor por meio "Dos vinhose dessa espécie típica de espumante - a cava”.

$\mathrm{O}$ roteiro da cava constitui um atrativo turístico para europeus e apreciadores da boa bebida. Para familiarizar o leitor, o discurso imagético recorre à figura da similitude para, com fotos de outras rotas enólogas já conhecidas, como a tradicional e badalada route du champagne, dotar de credibilidade o destino gastronômico oferecido. A familiaridade com o leitor é outra vez

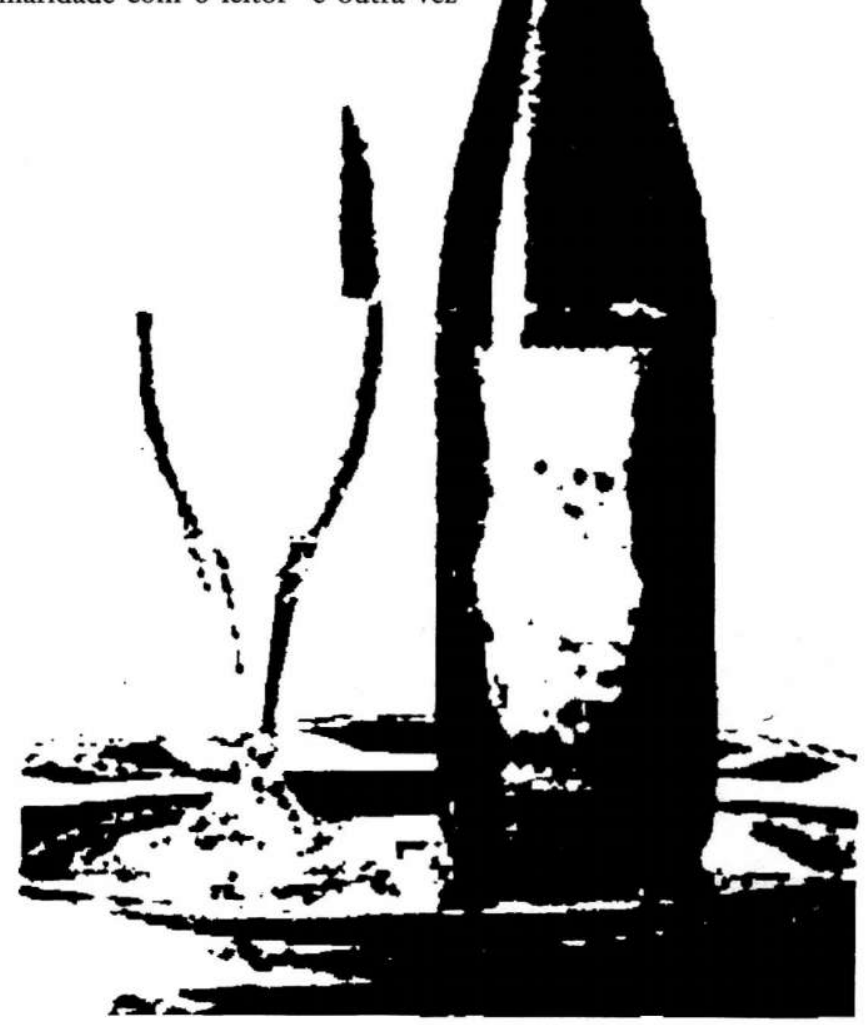


acionada na narrativa ao relacionar o champagne como "prima próxima da cava, que há décadas abre suas fábricas para turistas e gastrônomos". A matéria destaca a importância da gastronomia no turismo da Espanha e chama a atenção para o crescimento do interesse turístico pela rota da bebida, culminando com a abertura de um escritório de turismo do governo da regiāo. Esse escritório tem como meta "aumentar o número de turistas na região a médio prazo". O "negócio da cava" aparece detalhado no suplemento, com os seguintes dados sobre a popularidade da bebida no mundo e especialmente nos países da América Latina:

No Brasil, por exemplo, foram compradas 232.664 garrafas da bebida em 2003. número $9 \%$ maior do que o registrado em 2002. Já a Argentina registrou um salto de $300 \%$ no consumo do produto no mesmo período.

Destacando uma das maiores vinícolas espanholas na produção da cava - Codorniu - a notícia agrega valor cultural ao destino turístico/ gastronômico, ao sublimar em manchete:

"Casa de Gaudi serve de QG para rota enóloga".

Acompanhando o título, três fotos da fachada e do interior do prédio central da produtora de espumantes conhecida como a "catedral da cava", numa analogia à série de igrejas projetadas pelo católico arquiteto na Espanha e na França, com o sugestivo subtítulo: "Celas que acolhem cava durante o processo de envelhecimento carregam turista à idade média" . A narrativa noticiosa orienta os sentidos e as significaçóes da matéria, ao singularizar os elementos que beneficiam a produção de cavas no mediterrâneo:

A brisa mediterrânea é tida como um dos fatores que beneficiam as vinhas que brotam destes municípios. Ali, desenvolvem-se sete espécies diferentes de uvas habilidosamente manipuladas pelos produtores locais. As do tipo garnatxa vermelha e monastrell, por exemplo, só săo utilizadas na fabricação das cavas tipo rose.
Além das uvas locais, outro componente destacado como garantia do sabor da cava é o modo de armazenamento, que se assemelha ao da "idade média, as garrafas são estocadas em celas subterrâneas - verdadeiros túneis repletos delas mergulhando o visitante numa densa atmosfera de tradição secular".

Associando a rota das cavas ao turismo cultural, a reportagem enfatiza que no Museu da Cava o leitor/turista encontrará "... exibição de peças relacionadas ao consumo de vinho, passando por prensas do século 19, barris de madeira medievais, cartazes publicitários do século 20 e jarras de varas épocas da história".

No centro da terceira página do caderno dedicado à Espanha, o leitor será surpreendido com o título: "Chef catalão injeta química na alta cozinha". Escrito especialmente para os leitores preferenciais do suplemento, "os paulistanos poderão conferir o talento do chefJordi Butrón, do restaurante-escola de Barcelona, Esprai Sucre". Famoso por transformar sobremesa em prato principal, o gastrônomo tem assessoria de uma equipe de químicos responsáveis por "criar novas texturas para velhos sabores" com o propósito de divertir o comensal, pois, na concepção do chef, "o primeiro mandamento da gastronomia é fazer as pessoas felizes", como afirmou à revista Época, de maio de 2000. Assim, ele inventa caipirinhas com aspecto de massa folhada, polenta gelada e espumas aromáticas.

No final da reportagem, fecundando o imaginário do leitor com a nova gastronomia espanhola, o chefsegreda o menu que preparou para op casamento do príncipe de Astúrias, futuro rei da Espanha, realizado em maio passado, dois dias antes da veiculação do suplemento, conferindo atualidade informativa ao menu:

Pastel de queijo manchego, ananás, tomilho e leite picante com limăo, maçă verde, rúcula e Kefir. Brotos de aspargos brancos de Tudela com trufas de verăo e sua sopa; peixe-sapo com favinhas à menta, ravióli ibérico de tomate e vinagre de xerez; peito de pato e escabeche ligeiro ao vinho com purê de limão. 
Sublinhando as inovações químicas do gastrônomo em sua cozinha, a reportagem enfatiza o apoio que o profissional recebe de universidades $\mathrm{e}$ governos, que financiam pesquisas que produzem experiências explosivas,

...por exemplo, o chef injeta azeite de oliva e água do mar no miolo do pão assado e a massa arrebenta na boca. Mas o experimento mais conhecido e copiado do catalão é uma espuma leve e concentrada, produzida a partir da mistura de gelatina com um suco de frutas ou legumes, realizada num sifão.

A construção da imagem da gastronomia

As matérias referentes à gastronomia e ao turismo são de natureza promocional de empresas, restaurantes ou determinados tipos de cozinha. Em $90 \%$ das matérias analisadas para esta investigação são os jornalistas, seguidos pelos empresários e profissionais (donos de restaurantes, chefes de cozinha, proprietários de cafés e bares), que encontram espaço para veiculação do seu discurso na imprensa. Leitores, consumidores e freqüentadores não têm espaço nas matérias sobre turismo e gastronomia, além dos poucos profissionais envolvidos no setor. Essa lacuna discursiva reflete-se na orientação das reportagens, que silenciam o consumidor.

Questôes referentes à segurança alimentar $\mathrm{e}$ à higiene no processamento $\mathrm{e}$ acondicionamento dos alimentos não encontram espaço nos discursos sobre turismo e gastronomia nos cadernos analisados. Os bons estabelecimentos são classificados como "charmosos", possuidores de "pratos originais" e apresentam boa relação "serviço e preço". Dentro desse enquadramento discursivo, percebe-se que a pauta jornalística está centrada no produto a ser oferecido, e não na plena informação do leitor.

Ao desconsiderar as normas de segurança alimentar como critério valorativo para classificar os bons restaurantes, bares, cafés e buffets omitese, ao leitor/consumidor, a legislaçāo em vigor no setor, silenciando os direitos do consumidor e o respeito ao turista. Deixando de informar ou trabalhar a informação jornalística com todos pólos envolvidos, o discurso jornalístico em circulação assenta-se na superficialidade noticiosa da aparência, esquecendo-se de que na gastronomia aparência e essência são fatores determinantes e ralacionais.

A imagem da gastronomia nos jornais analisados, dessa forma, reduz-se |à "boa culinária", simplificando o fazer gastronômico e os processos envolvidos desde o plantio até o consumo dos alimentos. Poucos profissionais envolvidos no setor sāo ouvidos nas reportagens e matérias dedicadas ao assunto nas ediçóes. Químicos, nutricionistas, agentes sanitários, agricultores, tecnólogos de alimentos, biólogos, bioquímicos, médicos não se configuram com atores e fontes para jornalistas e editores das matérias sobre gastronomia.

Silenciando o consumidor como um cidadão e desconsiderando a complexidade da gastronomia, o leitor é submetido a uma informação parcial e tendenciosa, orientada para o consumo desenfreado de "coisas e lugares", como adverte Mendonça $(2003: 33)^{8}$. A mercantilização da cultura e da natureza é, portanto, parte integrante $e$ característica do desenvolvimento do turismo nas sociedades contemporâneas.
8 Mendonça, M.Luisa. Turismo sustentável: classes sociais $e$ subjetividade. In: Tânia Montoro (org.) Cultura do turismo: desafios e práticas socioambientais.

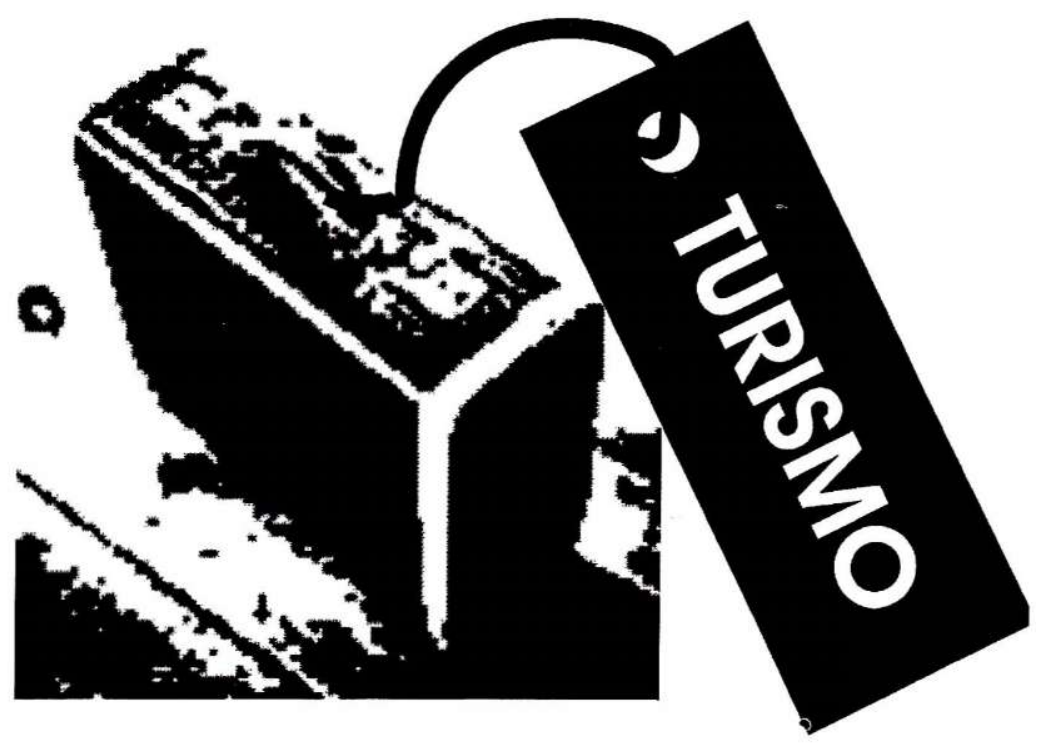




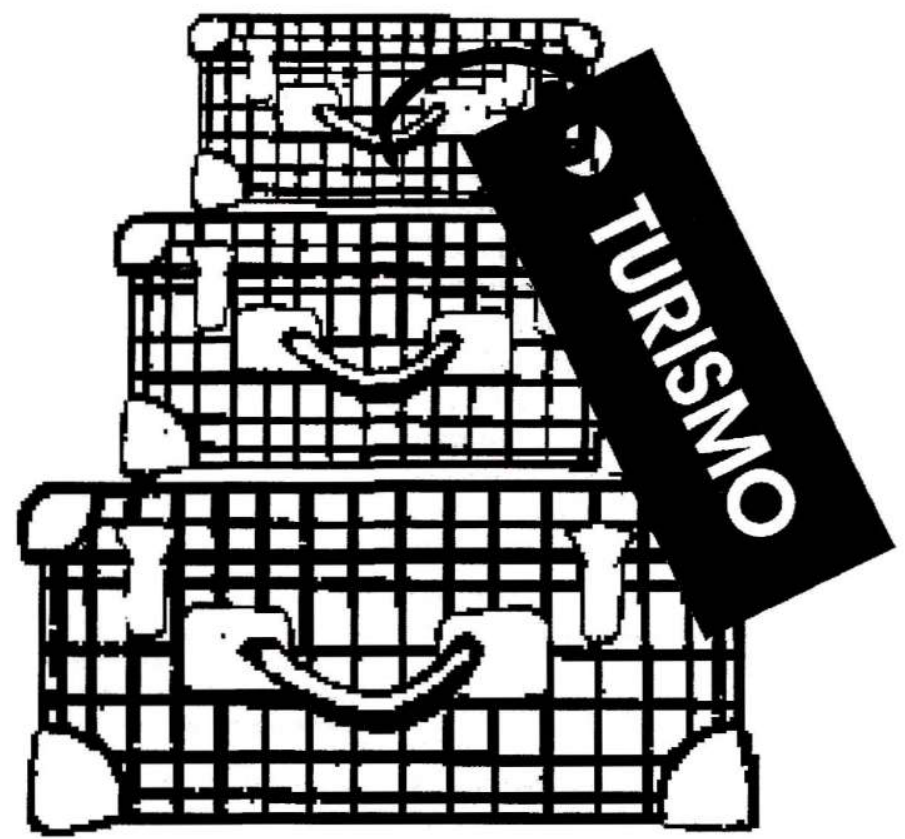

Bens culturais, simbólicos, meio ambiente natural, pessoas, tudo passa a ser incorporado como mercadoria vendável, com irresistível apelo de consumo.

Observa-se que, mesmo com a importância da segurança alimentar para segmentos expressivos do turismo (terceira idade, portadores de necessidades especiais, obesos, diabéticos), o discurso sobre a gastronomia nos cadernos de turismo não incorpora essa demanda em suas pautas. Pelo contrário, apesar do valor agregado entre turismo, cultura e gastronomia, a imagem da gastronomia ainda está ancorada somente no suporte das técnicas culinárias, impossibilitando ao turista/leitor desfrutar dos prazeres da mesa.

Verificou-se também que as discussóes da agenda pública brasileira que causam impactos diretos na gastronomia, como plantio de alimentos geneticamente transformados, transgênicos, redução de agrotóxicos na lavoura, poluição de rios e mares, crescimento acelerado do consumo de alimentos com alto teor de gordura e baixo teor nutricional, a relaçáo entra hábitos alimentares e qualidade de vida, são se encontram entre as preocupaçōes das pautas destinadas à gastronomia nas edições analisadas. Quando muito aparecem em pequenas notas promocionais de "vinho que reduz o mau colesterol" ou um hotel verde que tem cultivo de "hortaliças sem agrotóxicos".

Observando sem sistematização rigorosa, o caderno de turismo, nos anos anteriores a 2004, mostra que a gastronomia vem conquistando espaço no jornalismo impresso e na programação de televisão. Proliferam programas dedicados a oferecer uma hora na cozinha com chefs de todo mundo. Os hotéis investem na mídia audiovisual para promover "Como água para chocolate", "Chocolate" e " Dona Flor e seus dois maridos", em que Sônia Braga, numa atuação exemplar, é uma professora de culinária. A comida continua a ser atrativo principal dos serviços oferecidos pelo trade de turismo.

Por último, é importante destacar que a gastronomia integra a cultura do turismo como processo e como produto. Como processo, pelo qual um povo se identifica consigo próprio e com suas formas de vida; a autenticidade. Como produto, pela operacionalização de um conjunto de recursos materiais e simbólicos oferecidos de forma organizada e regular num determinado tempo e lugar.

No campo do turismo cultural, a gastronomia assume particular importância na construçāo da imagem de um local ou país, influencia na avaliaçăo positiva ou negativa de uma estada, é intérprete de uma cultura representada por hábitos alimentares e, especialmente, funciona como veículo de comunicação de imagens que fecundam nosso imaginário nas únicas linhas saborosas dos jornais brasileiros.

\section{Abstract}

This text presents the result of a reseach about how gastronomy is presented in touristic supplement of some of the most important brazilian newspapers. The author conceives news in its important role on the construction of social representations of identities and cultures, and explains how the ways of presentation of the news and their hierarchy in the 
newspapers lead to some senses, pretending to be the "natural" way of conceiving food and gastronomy.

Key words: Culture, tourism, gastronomy.

\section{Bibliografia}

ANDRADE, A. e BOSI, M.L.M. (2003) Mídia e subjetividade: impacto no comportamento alimentar feminino. Revista Nutriçāo, número 12, pp.117125, jan/março, Campinas.

Carneiro, H.(2003) Comida e sociedade: uma história da alimentação. Ed. Campinas, Rio de Janeiro.

FILHO, C. M. (2000) Jornalismo: a saga dos cães perdidos. Série comunicação, Hacker ed, São Paulo.

GASTAL, S. e CASTROGIOVANNI, A. C. (org.) Turismo na pós-modernidade. Coleção Comunicação. Ed. Edipucrs, Porto Alegre, 2002.

GARCIA, W. D. (2003) Reflexos da globalizaçăo na cultura alimentar: consideraçôes sobre as mudanças na alimentação urbana. Revista Nutrição, n. 16, pp483-492, out./dez. Campinas.

MONTORO, T. S. (org.) Cultura do turismo: desafios e práticas socioambientais. Ed. Thesaurus, Brasília, 2003.

Oliveira, A. C. e fechine, Y. (org.) Imagens Técnicas. Hacker ed. São Paulo, 1998. POULAIN, J.P. e PROENÇA R.P.C. Reflexóes metodológicas para o estudo das práticas alimentares. Revista Nutrição, n. 16, pp.365-386, out/dez., Campinas.

SOOD, R. STOCKDALE, G e ROGERS, E. (1987) How the news media operate in natural disasters. Journal of communications, v. 37, n.3.

SHUDSON, M. (1988) What is a reporter? The private face of public journalism. In James Carey (ed) Media, myth and Narratives: television and the press. Newbury Park: Sage publications. TRAQUINA, N. (2003) O estudo do jornalismo no século XX. Ed, Unisinos, Sāo Leopoldo, Rio Grande do Sul.
(2000) A redescoberta do

poder do jornalismo: análise de textos da teoria do agendamento. Ed, Minerva, Coimbra.

Jornais consultados para a pesquisa

Correio Braziliense:

ediçóes de março (2004) 03;10;17;24;31

abril (2004) 07;14; 21;28

maio (2004) 12;19;26

O Globo: ediçōes de março (2004)

$04 ; 11 ; 18 ; 25$

abril (2004) 01;08;22;29

maio(2004) 12;19;26

Folha Turismo: ediçóes de março (2004)

$01 ; 08 ; 15 ; 22 ; 29$

Abril (2004) 05;12;19;26

Maio (2004) 03;17;24

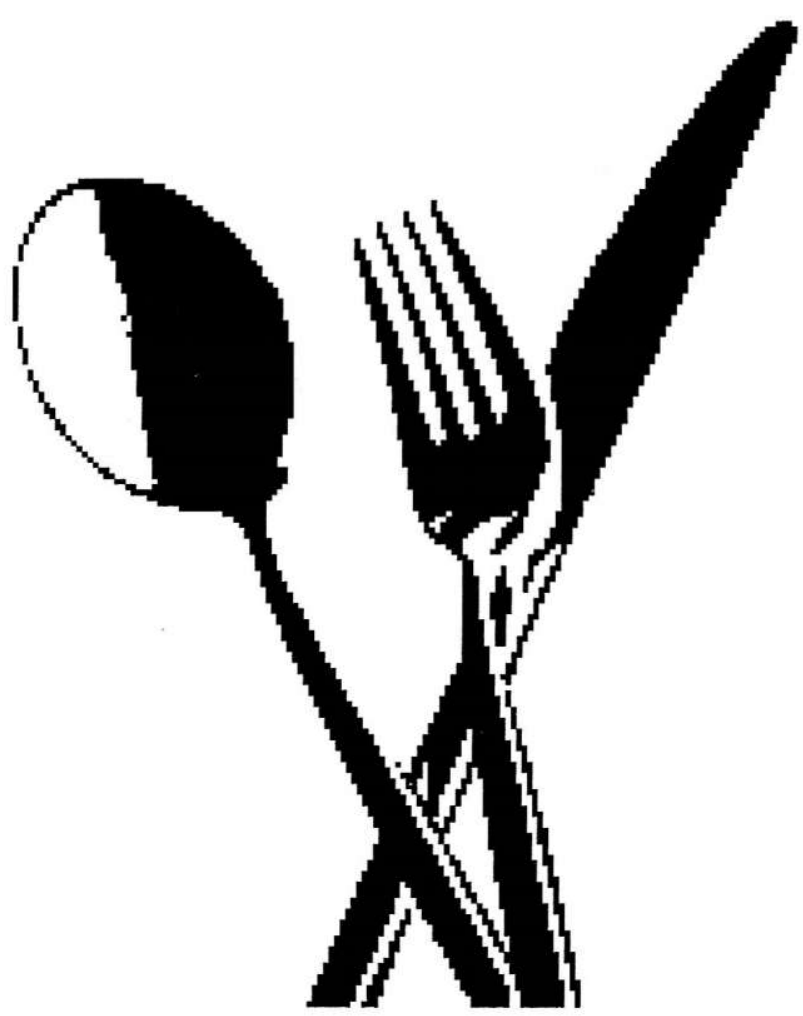

